\title{
- Prácticas informativas en tiempos de Covid-19: procesos de promoción de la salud y derecho a la información en el norte de la Patagonia argentina
}

\author{
Práticas informativas em tempos de Covid-19: processos de \\ prevenção, desinformação e direito à comunicação no norte da \\ Patagônia argentina \\ Informational practices in times of Coronavirus. Health promotion \\ processes and right to information in the north of Patagonia, \\ Argentina
}

\author{
Pablo Schleifera,* \\ Fabián Bergero ${ }^{a}$ (i) \\ Julia Kejnera (iD) \\ Omar Gonzalez ${ }^{\mathrm{a}}$ (D)
}

\begin{abstract}
RESUMEN: Este artículo se propone indagar en las prácticas de consumo informativo respecto del COVID19 en las provincias del norte de la Patagonia argentina durante el período de Aislamiento Social Preventivo y Obligatorio que decretó el gobierno nacional. Mediante el análisis de dos encuestas realizadas por el Observatorio de Comunicación y Temáticas Sociales (FadeCS-UNCo), interesa conocer la relación entre el funcionamiento de los medios y soportes comunicacionales oficiales y privados y los cambios de hábitos informacionales de la población, en tanto pueden generar mejoras en los procesos de prevención colectiva y derecho a la comunicación o bien procesos de desinformación.
\end{abstract}

Palabras clave: Prácticas Informativas; Derecho a la Información; Redes Sociales; Medios de Comunicación; Coronavirus.

RESUMO: Este artigo tem como objetivo investigar as práticas de consumo informativo referentes ao COVID-19 nas províncias do norte da Patagônica argentina durante o período de Isolamento Social Preventivo e Obrigatório que foi decretado pelo governo nacional. Diante das análises de duas enquetes realizadas pelo Observatorio de Comunicación y Temáticas Sociales (FadeCS-UNCo), é interessante conhecer a relação entre o funcionamento dos meios e suportes de comunicação oficiais e privados e as mudanças de hábitos informacionais da população, como eles podem gerar melhorias nos processos de prevenção coletiva e direito à comunicação ou processos de desinformação.

Palavras-chave: Práticas Informativas; Direito à Informação; Redes Sociais; Meios de Comunicação; Coronavírus.

ABSTRACT: This article aims to investigate the informative practices regarding COVID-19 in the northern provinces of Argentine Patagonia during the period of Preventive and Compulsory Social Isolation decreed by the government. Through the analysis of two surveys carried out by the Communication and Social Issues Observatory (FadeCS-UNCo), it is interesting to know the relationship between the functioning of the official and private communication media and the changes in the information habits of the population, as they can generate improvements in the processes of collective prevention and the right to communication or processes of disinformation.

Keywords: Informative Practices; Right to Information; Social Networks; Medias; Coronavirus.

\footnotetext{
a Facultad de Derecho y Ciencias Sociales, Universidad Nacional del Comahue, Río Negro, Argentina.

*Correspondencia para/Correspondence to: Pablo Schleifer: Endereço: Mendoza y Perú (CP8332)-Roca-Fiske, Río Negro, Argentina. E-mail: pablo_schleifer@yahoo.com.ar.

Recibido en/Received: 09/06/2020; Aprobado en/Approved: 06/11/2020.

Artículo en acceso abierto bajo una licencia CC BY 4.0 Internacional $@(1)$
} 


\section{INTRODUCCIÓN}

En diciembre de 2019, la ciudad de Wuhan, China, tuvo el primer brote de contagios por Covid-19 y en marzo ya se detectó en Argentina el primer paciente con la enfermedad'. Con el anuncio de 128 casos confirmados y tres personas fallecidas por Covid-19, el gobierno actuó rápidamente con el fin de proteger la salud pública y aplicó el 19 del ese mes el Aislamiento Social Preventivo y Obligatorio (en adelante ASPO) para todo el territorio nacional. Esta medida excepcional que determinó el gobierno nacional implicó que la población que habita este territorio o que temporalmente se encontraba aquí, debía permanecer en sus domicilios habituales, sólo pudiendo realizar desplazamientos mínimos e indispensables para aprovisionarse de artículos de limpieza, medicamentos y alimentos.

Esta medida produjo fuertes cambios de hábitos en la población argentina y fue acompañada del cierre de fronteras y de la aprobación de un paquete de políticas asistenciales dirigidas a trabajadoras/es de bajos ingresos y el sector informal. Asimismo, el gobierno nacional activó una campaña fuerte de concientización sobre medidas de prevención y cuidado colectivo frente al virus, en la que los medios de comunicación y las Redes Sociales jugaron un rol importante. A partir de ese momento comenzó a difundirse un parte diario nacional televisado que, en algunas provincias, como Río Negro, también se implementó con la misma frecuencia de emisión que el de la Nación. En ese contexto se observó un fuerte consenso social frente a la imagen del presidente Alberto Fernández y el Ministerio de Salud, en parte porque el Estado asumió el rol protagónico de proteger la salud de la población a través de medidas de prevención y fortalecimiento de los hospitales públicos, pero también porque el conjunto de los distintos actores sociales -empresarios, partidos opositores, medios de comunicación, agentes de salud, educadores, intelectuales, por mencionar sólo algunos- colaboraron en conformar un sentido de unidad frente a la pandemia ${ }^{2}$.

Asimismo, ese fuerte acatamiento social que tuvieron las medidas en los primeros días de ASPO puede comprenderse mejor en el marco de la coyuntura política del país y del estado de las políticas públicas de salud al momento de desarrollo de la pandemia. El presidente, Alberto Fernández, asumió el gobierno a fines de 2019, luego de un triunfo electoral del Frente de Todos (coalición política de centro-izquierda con mayoría peronista) frente a Mauricio Macri, quien buscaba su reelección y representaba a Juntos por el Cambio (colación de derecha, mayoritariamente integrada por integrantes de Cambiemos). De manera que al momento de decretar el ASPO el gobierno sólo llevaba tres meses en ejercicio de sus funciones y las condiciones del sistema sanitario de salud las heredaba de la gestión macrista. Durante el período 20152019, el gobierno de Mauricio Macri había bajado el rango de Ministerio de Salud a Secretaría; ; recortó una docena de programas, entre ellos los vinculados a la prevención y control de enfermedades endémicas y los de cobertura de emergencias

\footnotetext{
${ }^{1}$ Los primeros contagiados en Argentina estaban vinculados con viajes al exterior, de manera que las acciones iniciales para frenar la propagación del virus estuvieron dirigidas al cierre de las fronteras y al control de los contactos estrechos de personas que hubieran vuelto de viajes.

2 Un ejemplo de este consenso construido en torno a la unidad de la ciudadanía argentina frente al virus fue la acción que llevaron adelante los distintos diarios del país que, el 19 de marzo de 2020, decidieron publicar todos la misma tapa con el titular: "al virus lo frenamos entre todos". La iniciativa fue de la la secretaría de Medios y Comunicación Pública de la Nación, junto a la Asociación de Entidades Periodísticas Argentinas (Adepa) y fue la primera vez en la historia del país que todos los periódicos tuvieron una portada idéntica.
}

3 https://www.infobae.com/opinion/2018/09/09/nueva-secretaria-de-salud-mas-dudas-que-certezas/ 
sanitarias ${ }^{4}$; compró y almacenó vacunas que no otorgó a la población y dejó vencer ${ }^{5}$ y suspendió o paralizó la construcción de los hospitales que se habían realizado durante el último gobierno de Cristina Kirchner, cuyo avance de obra se acercaba al 90\%, en la mayoría de los $\operatorname{casos}^{6}$. De manera que el sistema de salud argentino, al momento en que se desarrolló la pandemia se encontraba diezmado y con muy poca capacidad de respuesta ante esta situación. Frente a ello, el gobierno de Alberto Fernández creó un discurso que privilegió la salud pública como obligación del Estado y recuperó el protagonismo de este último como actor central que prioriza el cuidado, la salud y la vida de las personas.

En este escenario la pandemia y las medidas tomadas por el gobierno nacional supuso una serie de alteraciones en las prácticas sociales y culturales de la población. En los límites de este trabajo interesa analizar las prácticas de consumo informativo de la población en Río Negro y de Neuquén, en tanto espacios gobernados por partidos provinciales que si bien en determinadas coyuntuas se han alineado al gobierno nacional, mantienen autonomía partidaria con este último. Asimismo, nos detenemos en los modos de consumo informacional respecto del Covid-19 puesto que, en buena medida, el grado de acatamiento depende de políticas de prevención y de promoción de la salud que suponen siempre procesos comunicacionales (DIAZ, URANGA, 2011).

De manera que, entendemos, hay por lo menos tres instancias comunicacionales a las cuales prestar especial atención a los efectos de conocer más de cerca las características que en un territorio determinado adquieren esos procesos de prevención y promoción. Por un lado, las estrategias comunicacionales de los distintos niveles del Estado (nacional, provinciales y municipales) en la construcción de la información oficial en diversos planos, y las prácticas mediante las cuales la población las consume. Por otro lado, el rol de los medios de comunicación y periodistas de alcance nacional, regional y local. Estos juegan un papel central en la traducción y adaptación de las decisiones a la realidad particular de los territorios subnacionales, así como educan (o des-educan) e informan (o des-informan); pues, no solo inciden en la agenda pública de salud (OBREGÓN, 2010) sino que, como sostienen Feo Acevedo y Feo Istúriz (2013), tienen un fuerte impacto en la salud colectiva e individual toda vez que son fundamentales en la conformación de creencias y comportamientos. Finalmente, si bien la difusión y circulación de información concreta en temas de salud a través de las redes sociales puede ser bastante deficiente (ALCÁNTARA LÓPEZ, 2015) o confusa, constituye otra instancia imprescindible para conocer e impulsar los procesos de prevención y promoción por los efectos que esa información/desinformación puede tener en la salud colectiva (ESPINOZA PORTILLA, MAZUELOS CARDOZA, 2020).

Para reconstruir y comprender estos procesos e instancias hemos realizado desde el Observatorio de Comunicación y Temáticas Sociales (FaDeCS-UNComahue) tres relevamientos antes y durante el período de ASPO en el norte de la Patagonia argentina. El primer estudio es de noviembre de 2018 y los datos fueron procesados y

\footnotetext{
4 https://www.lanacion.com.ar/politica/recortes-en-partidas-sensibles-del-area-de-salud-nid2183713

5https://www.infobae.com/politica/2020/08/19/hallaron-cuatro-millones-de-vacunas-vencidas-en-un-frigorifico-enconstitucion/

${ }^{6}$ http://soberaniasanitaria.org.ar/una-manada-de-elefantes-blancos/

7 Por ello, "el abordaje de problemas en el campo de la salud ha evidenciado un renovado interés por la comunicación" (ALBARDONEDO, CUBERLI, 2009, p. 1).
} 
publicados en el primer trimestre de 2019; se realizó con la población de la región del Alto Valle de Río Negro y Neuquén sobre un total de los 338 casos válidos ${ }^{8}$.

Para el segundo y el tercero, confeccionamos cuestionarios auto-administrados que fueron distribuidos de manera descentralizada en ambas provincias, garantizando representatividad de género, edad y zona geográfica. A partir de 577 casos pudimos arribar a las siguientes conclusiones: 1) el nivel de exposición a información aumentó cuantitativa y cualitativamente aunque disminuyó el consumo de noticias sobre Covid19 en la última etapa; 2) creció el consumo de medios de flujo continuo, así como se registraron cambios en los modos de recibir, distribuir e interactuar con la información de salud; 3) se verificó un alto nivel de monitoreo ciudadano de la información a través de la verificación de fuentes y de la incorporación de nuevos medios y plataformas a la dieta informativa; 4) se asiste a una etapa de descreimiento de las noticias que circulan por redes sociales cuando éstas provienen de fuentes desconocidas.

\section{PRINCIPALES ASPECTOS TEÓRICO-METODOLÓGICOS}

Entendemos que los medios de comunicación y el periodismo constituyen actores de suma importancia en la construcción de "realidades" puesto que cuentan con una formidable eficacia en la circulación de puntos de vista sobre el mundo social; contribuyen a la formación de "opinión pública" (CASTELLS, 2008), a la valoración de los hechos, sucesos o fenómenos sociales. Las prácticas de consumo informativo de la población y la credibilidad sobre los discursos de esos medios, resultan una arista clave para comprender su incidencia en los procesos de prevención de la salud (OBREGÓN, 2010; FEO ACEVEDO, FEO ISTÚRIZ 2013).

También los flujos de información a través de las Redes Sociales constituyen elementos centrales. La credibilidad en la información recibida a través de las Redes Sociales es un tema que se viene investigando desde diversos ámbitos; en general se pone énfasis en la relación que existe entre la confianza y la fuente en que se origina la información, más que en el canal de distribución. Así aparece en los estudios de Arias-Robles (2014), Sánchez-Navarro y Aranda (2011) y de Samuel-Azran y Hayat (2019) quienes concluyen que si bien la fuerza de enlace entre receptor y remitente "nada tiene que ver con la credibilidad real del artículo informativo (...) la fuerza de enlace mediatiza la percepción que el receptor tiene del ítem compartido" (SAMUEL-AZRAN, HAYT, 2019, p. 79). En el marco de la pandemia, Pere Masip y otros determinaron que la audiencia española relegó a las redes sociales al último nivel de confianza (63\%) detrás de la televisión $(81,1 \%$ y y los diarios digitales $(74,7 \%)$. Similar fue la conclusión del estudio de Reuters Institute y la Universidad de Oxford (2020) en siete países, incluida la Argentina: "mucha más gente confía en noticias e información sobre el coronavirus publicadas en los medios que en lo que encuentra en redes sociales", con brechas de hasta el 33 por ciento.

Ahora bien, las provincias de Río Negro y de Neuquén se sitúan geográficamente en el norte de la Patagonia argentina. A los efectos de lo que aquí interesa, conviene resaltar que se trata de territorios muy amplios y extensos con baja densidad demográfica ${ }^{9}$ y

\footnotetext{
8 El informe completo está disponible en línea en el siguiente enlace: https://medialabpatagonia.org/wpcontent/uploads/2019/06/ENCUESTA-CONSUMO-DIGITAL-ALTO-VALLE-1.pdf El objetivo de este primer estudio fue actualizar la información sobre prácticas de consumo informativo en la región, que se venía colectando desde hace más de una década (ROST et al.; 2008: BERGERO, 2013; SOLARO, 2016).

9 Según el Censo 2010, elaborado por el Instituto Nacional de Estadística y Censos, la provincia de Río Negro cuenta con una densidad de 3.49 hab./km2, mientras que la provincia de Neuquén con una densidad de 5.85 hab./km2.
} 
concentración de la población en algunos pocos centros urbanos ${ }^{10}$ en los cuales, además, se ubican los principales medios de comunicación regionales; a la inversa, en las regiones menos pobladas y más alejadas de esos centros, los medios de comunicación y los sitios de noticias en internet con contenidos locales son escasos y, a veces, inexistentes (SCHLEIFER, 2018).

La investigación que se presenta a continuación es un estudio exploratorio no probabilístico por bola de nieve $e^{11}$; para ello se elaboraron y ejecutaron dos relevamientos con un espacio temporal de cuatro semanas ${ }^{12}$. El primero nos permitió conocer las prácticas de consumo informativo iniciales, apenas pasada la primera semana de confinamiento signada, como veremos, por la necesidad de instruirse y el temor ante lo desconocido. El segundo nos posibilitó identificar continuidades, cambios y rupturas en esas prácticas y construir un diagnóstico más detallado respecto de los procesos comunicacionales de promoción y prevención.

Los cuestionarios se realizaron con un formulario autoadministrado de Google; el primero se denomina Covid-1 y fue consumado en tres días, desde el lunes 23 al miércoles 25 de marzo, sobre un total de 244 casos válidos tomados en 18 ciudades $^{13}$. El segundo se denomina Covid-2 y fue realizado del lunes 13 al miércoles 15 de abril de 2020 sobre un total de 333 casos válidos tomados en 20 localidades $^{14}$.

Ante la imposibilidad de realizar encuestas presenciales, se optó por esta metodología de distribución que entraña ciertos sesgos de los que se debe dar cuenta a los efectos de posibilitar una adecuada lectura de los datos que arroja la encuesta. En primer lugar, el envío de formularios a través de redes sociales, WhatsApp y correos electrónicos, circunscribe el universo de personas destinatarias a quienes tienen acceso a estos medios y sistemas; de manera que el alcance se limita al "microclima" de la población que tiene posibilidades de conectarse habitualmente (acceso a internet, tecnología disponible y alfabetización digital).

Al mismo tiempo, se solicitó a quienes les fue enviado el cuestionario que lo compartieran entre sus contactos y que -a su vez- esas personas lo renviaran a los/as suyos/as; así se produce cierto grado de apertura por el efecto bola de nieve, lo cual supone la imposibilidad de ajustar la encuesta a las cuotas deseadas $y$, al mismo tiempo, una posibilidad de surcar el "efecto de comunidad".

En otros términos, el tipo de procedimiento y los riesgos metodológicos a los que se enfrentaba esta investigación eran conocidos previamente. Sin embargo, se decidió llevarla a cabo con estas características, para no sucumbir ante los obstáculos y abandonar la investigación (y por lo tanto no estudiar lo que se pretendía estudiar). Así, como afirma Pierre Bourdieu (2001) uno de los principales obstáculos con los que

\footnotetext{
10 Según el Censo 2010, en el departamento Confluencia, donde se sitúa la capital de la provincia del Neuquén, vive el $65.5 \%$ de la población de esa provincia. En Río Negro, el $52.9 \%$ vive en cuatro ciudades principales, mientras que el resto lo hace en 32 localidades.

${ }^{1}$ Se trata de una muestra dirigida, que implica procedimientos de selección informal (Hernández Sampieri, Fernández Collado, Baptista Lucio, 2006)

${ }^{12}$ Los Informes completos de estos trabajos se pueden ver en https://medialabpatagonia.org

${ }^{13}$ Localidades. Provincia de Neuquén: Neuquén Capital, Centenario, Plottier, Picún Leufú y Cutral Co. Provincia de Río Negro: Cipolletti, General Roca, Cinco Saltos, Allen, Viedma, Ingeniero Huergo, San Carlos de Bariloche, Sierra Colorada, Las Grutas Fernández Oro, Villa Regina, Los Menucos y Valcheta

14 Localidades. Provincia de Neuquén: Neuquén Capital, Centenario, Plottier, Cutral Có, Catriel, Buta Ranquil, Arroyito y Zapala. Provincia de Río Negro: Cipolletti, General Roca, Cinco Saltos, Allen, Viedma, San Carlos de Bariloche, Las Grutas, Fernández Oro, Villa Regina, General Enrique Godoy, El Bolsón y Choele Choel
} 
se encuentra la ciencia social reside en la "formidable brecha entre la obediencia estricta a las reglas de la buena conducta científica tal como las defiende la doxa metodológica enseñada en las universidades, y las verdaderas virtudes científicas" (BOURDIEU, 2001, p. 70) que implican, a veces, la necesidad de construir los propios objetos rompiendo con la "realidad" como se nos presenta. De modo que, la heterodoxia metodológica se torna tanto más necesaria en este contexto de pandemia.

Así, como se observa en los Gráficos 1 y 2, en términos generales los porcentajes de respuestas según identidad de género autopercibida (IG) y franjas etarias mantienen equivalencia en casi todos los puntos. La diferencia que se percibe en la menor cantidad de respuestas en la franja más joven y la mayor cantidad de respuestas en las franjas que van de los 40 a los 49 y de los 50 a los 59 años parece corresponderse, como veremos más adelante, con el aumento en la horas de exposición a la información sobre el Covid-19 y con los cambios en las prácticas informativas de esas franjas etarias.

Gráfico 1. Identidades

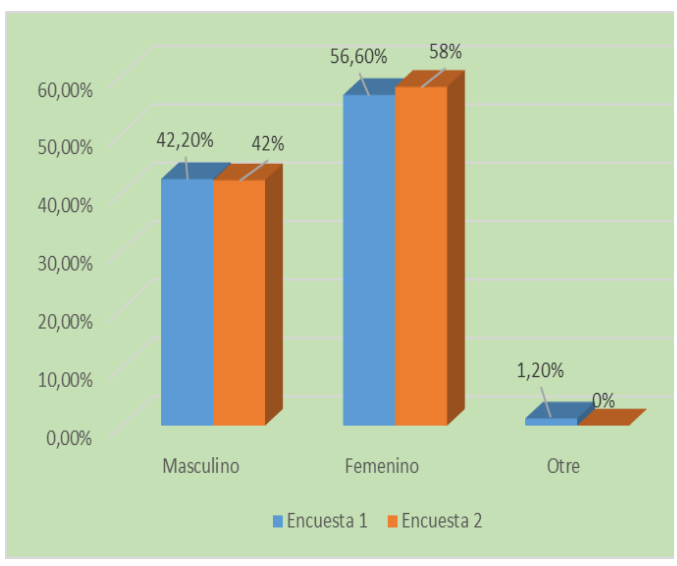

Gráfico 2. Franjas etárias

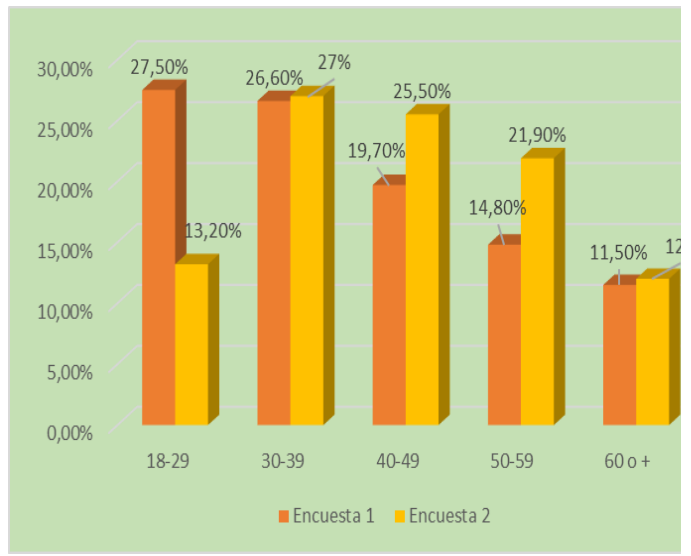

Fuente: Observatorio de Comunicación y Temáticas Sociales - FaDeCS - UNCO

\section{EXPOSICIÓN A LA INFORMACIÓN Y TIPO DE MEDIOS PARA EL CONSUMO}

Durante la primera semana de ASPO, casi un $80 \%$ de las personas encuestadas dijo estar más de tres horas por día expuesta a las noticias. La sobreinformación es un fenómeno propio de períodos de crisis como el actual, a la que contribuye el encierro. Así, como se ve en el Gráfico 3, las personas mayores de 60 están prácticamente un tercio de su tiempo expuestas a la información mientras que las personas mayores de 50 están más conectadas a la información que las más jóvenes: quienes están entre los 18 y los 29 años, se exponen menos a las noticias, lo que no significa que estén menos tiempo conectados/as. 


\section{Gráfico 3 - Exposición a las noticias de las personas encuestadas.}

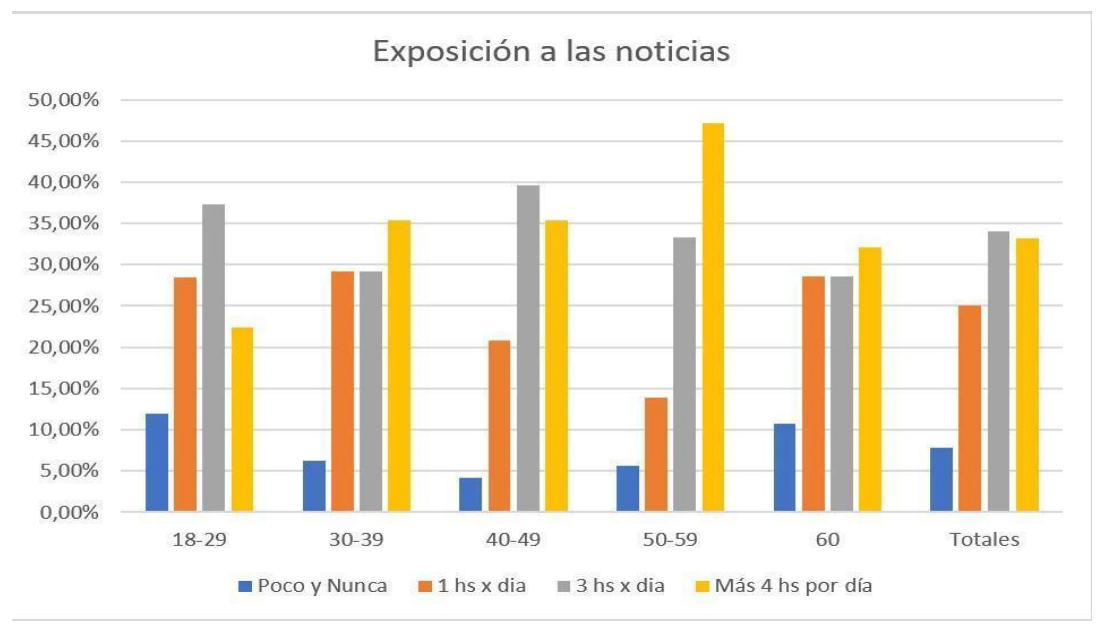

Fuente: Observatorio de Comunicación y Temáticas Sociales - FaDeCS - UNCO

Tres semanas después, el tiempo de exposición a los medios se mantuvo casi sin alteraciones $^{15}$. Pues los/as habitantes de la Patagonia norte que consumen información entre 1 y 3 horas diarias equivalen al $60 \%$ de la población encuestada. En este sentido, las mujeres tienen menos horas de exposición a la información sobre el coronavirus que los varones; mientras que a nivel general el 70,2 \% dice estar dos horas o menos frente a información relacionada con la Pandemia, el $60 \%$ de los varones lo hacen durante dos horas o hasta más de seis. La diferencia en la cantidad de horas de consumo informativo podría estar vinculada con la desigual distribución del trabajo doméstico y las tareas de cuidado familiar, las cuales podrían seguir recayendo principalmente sobre las mujeres (Cuadro 1).

\section{Cuadro 1- Cantidad de horas expuestas a las noticias referidas a COVID-19 según identidad de género autopercibida}

\begin{tabular}{|l|c|c|c|c|c|c|c|}
\hline \multirow{2}{*}{ Identidad autopercibida } & \multicolumn{6}{|c|}{ Exposición a información sobre Covid-10 (en horas) } \\
\cline { 2 - 8 } & $>1 \mathrm{hr}$. & $1 \mathrm{hr}$. & 2 hrs. & 3 hrs. & 4 hrs. & 5 hrs. & $<6$ hrs. \\
\hline Varón & $18,1 \%$ & $21,7 \%$ & $21,7 \%$ & $13,0 \%$ & $10,9 \%$ & $0,7 \%$ & $13,8 \%$ \\
\hline Mujer & $22,2 \%$ & $25,3 \%$ & $22,7 \%$ & $14,4 \%$ & $7,2 \%$ & $2,6 \%$ & $5,7 \%$ \\
\hline TOTAL & $20,5 \%$ & $23,8 \%$ & $22,3 \%$ & $13,9 \%$ & $8,7 \%$ & $1,8 \%$ & $9,0 \%$ \\
\hline
\end{tabular}

Fuente: Observatorio de Comunicación y Temáticas Sociales - FaDeCS - UNCO

Los sitios de noticias en la web son los medios preferidos para informarse, pero forman parte de una práctica "multi-medios": los suman a las redes sociales, a la televisión y a la radio. En las distintas franjas etarias la utilización de diferentes medios para informarse parece ser una constante, pues, efectivamente, todo indica que hay una

\footnotetext{
${ }^{15}$ El 14 de abril de 2020, Joshua Benton de Nieman Lab, daba cuenta de un amesetamiento de la atención de la gente sobre noticias relativas al Coronavirus en los Estados Unidos y lo atribuía a un fenómeno que denominaba "fatiga por coronavirus". El artículo podría indicar el camino que sigue la atención a la información específica en el Hemisferio Sur, en donde la pandemia impactó con más fuerza más tarde.
} 
estrecha relación entre la cantidad de horas que se pasan en búsqueda de información, la variedad de medios que recorren y de soportes que emplean. En otros términos, parece haber una búsqueda constante de información en una recorrida multimedial y multiformato.

Estos datos guardan correlación con los obtenidos en el Informe 2018 mencionado anteriormente, en el cual el diario papel se situaba como el formato menos utilizado de la región: un 18,1\% decía emplear ese medio. Allí ya se observaba que la exposición a los sitios de noticias en la web era de 79,9\%; a Redes Sociales 74,5\%; Radio del 55,4 \%; Televisión 48,1 \% y Diario de papel 18,1\% (Cuadro 2). Es decir que -en términos comparativos-, se produce una leve disminución en la exposición a sitios web y a redes sociales y aumenta fuertemente el consumo de noticias por televisión ${ }^{16}$.

Cuadro 2-Comparativa soportes y medios

\begin{tabular}{|l|c|c|}
\hline & 2018 & 2020 \\
\hline Sitios web de noticias & $79.9 \%$ & $69.7 \%$ \\
\hline Redes Sociales & 74.5 & $63.5 \%$ \\
\hline Televisión & $48.1 \%$ & $58.6 \%$ \\
\hline Radio & $55.4 \%$ & $32.8 \%$ \\
\hline Diario Papel & $18.1 \%$ & $5.3 \%$ \\
\hline
\end{tabular}

Fuente: Observatorio de Comunicación y Temáticas Sociales - FaDeCS - UNCO

En nuestro relevamiento de marzo de 2020, verificamos que la televisión había desplazado a la radio como plataforma de información: una curiosidad propia de esta etapa de aislamiento ${ }^{17}$. El aumento del consumo televisivo parece estar relacionado con la necesidad de informarse a través de medios de comunicación de flujo constante debido a dos razones: 1) el imperativo de contar con información actualizada y permanente y 2) la disponibilidad de tiempo de las familias para consumir un medio que requiere de mayor concentración (auditiva y visual).

Por otro lado, la disminución en la escucha de radio en tiempos de Covid-19 (que ya habíamos verificado en el informe Covid-1) podría vincularse a la prepotencia de la televisión encendida durante muchas horas en los hogares y con la disminución en el uso del audio portátil (música, radio, noticias). De ello se puede inferir que la gente pasa mucho tiempo conectada, pero concentró la exposición relativa a la expansión del virus a una hora o menos, que es el tiempo que dura un noticiero tradicional de tevé o un panorama informativo radiofónico convencional.

\footnotetext{
${ }^{16}$ Los datos coinciden con los del estudio “El impacto de la pandemia en la prensa" de Pepe Cerezo (2020), en el que se verifica un aumento del tiempo para leer noticias en plataformas digitales y de tiempo de permanencia.

${ }^{17}$ El tercer informe del equipo de Consumer Insight \& Transmedia de Ignis Media Agency sobre el consumo de medios en el marco de la pandemia indica que hubo un incremento en el consumo de TV y videos online.
} 


\section{INFORMACIÓN SOBRE EL COVID-19 EN LOS MEDIOS, TEMAS DE INTERÉS Y GRADOS DE CONFIANZA}

Como se observa en el Gráfico 4, las personas encuestadas afirman estar más expuestas a la información nacional y local. No obstante, casi el $60 \%$ revisan información en todos los órdenes, vale decir: lo que pasa en su localidad, en la región próxima, a nivel nacional y en el plano internacional. Es que, en efecto, todo parece indicar que desde la posición específica en los territorios del interior del país la atención no se centra en la información producida en las grandes metrópolis sino que, por el contrario, se establece una concatenación desde lo micro a lo macro; lo cual supone una especie de disposición a la comprensión global desde lo local de la problemática desatada con la pandemia ${ }^{18}$.

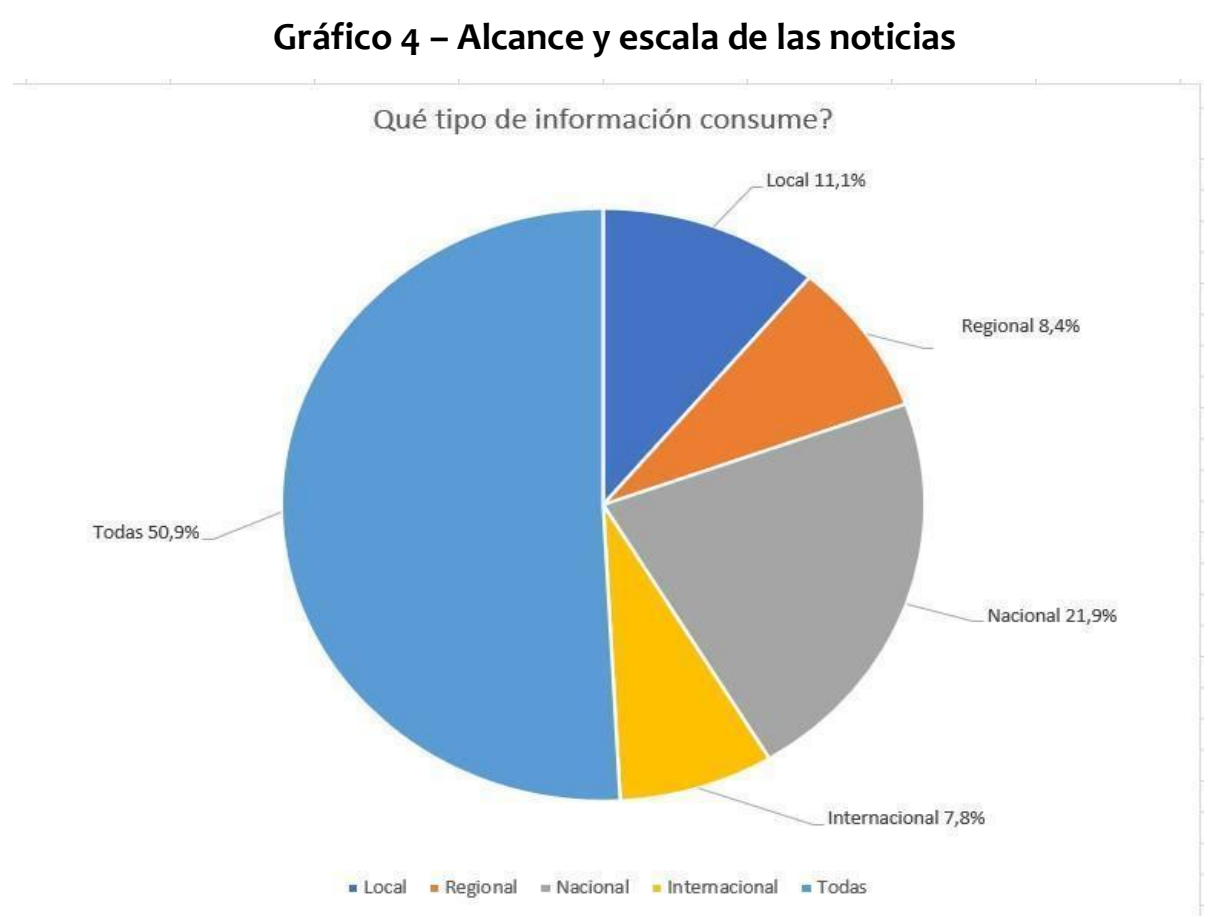

Fuente: Observatorio de Comunicación y Temáticas Sociales - FaDeCS - UNCO

Por ello, en un primer momento, el estudio Covid-1 demostraba que el $61,5 \%$ se interesaba fundamentalmente por las medidas de los gobiernos nacionales, provinciales y municipales a los efectos de conocer no solo los alcances de la ASPO en cada región y localidad sino, además, las medidas de prevención necesarias $(14,8 \%)$ para controlar la propagación del virus. En el segundo momento (Covid-2), un mes después de iniciada la cuarentena, la atención sobre la "curva" de la pandemia es lo que más interés despierta en casi todas las franjas etarias; en forma paralela el interés por las políticas económicas implementadas en todos los niveles estatales para paliar la crisis que provoca el ASPO y los avances de la ciencia para encontrar vacunas contra el COVID-19, comenzaron a ocupar mayor interés (Gráfico 5).

18 Numerosos estudios hablan de la proliferación de medios hiperlocales a nivel mundial y de la importancia de las agendas en las comunidades de pertenencia. Entre ellos, se pueden destacar los de López García; María Cruz NegreiraRey y Ana Rodríguez Vásquez (2016); López García (2008 y 2012). 


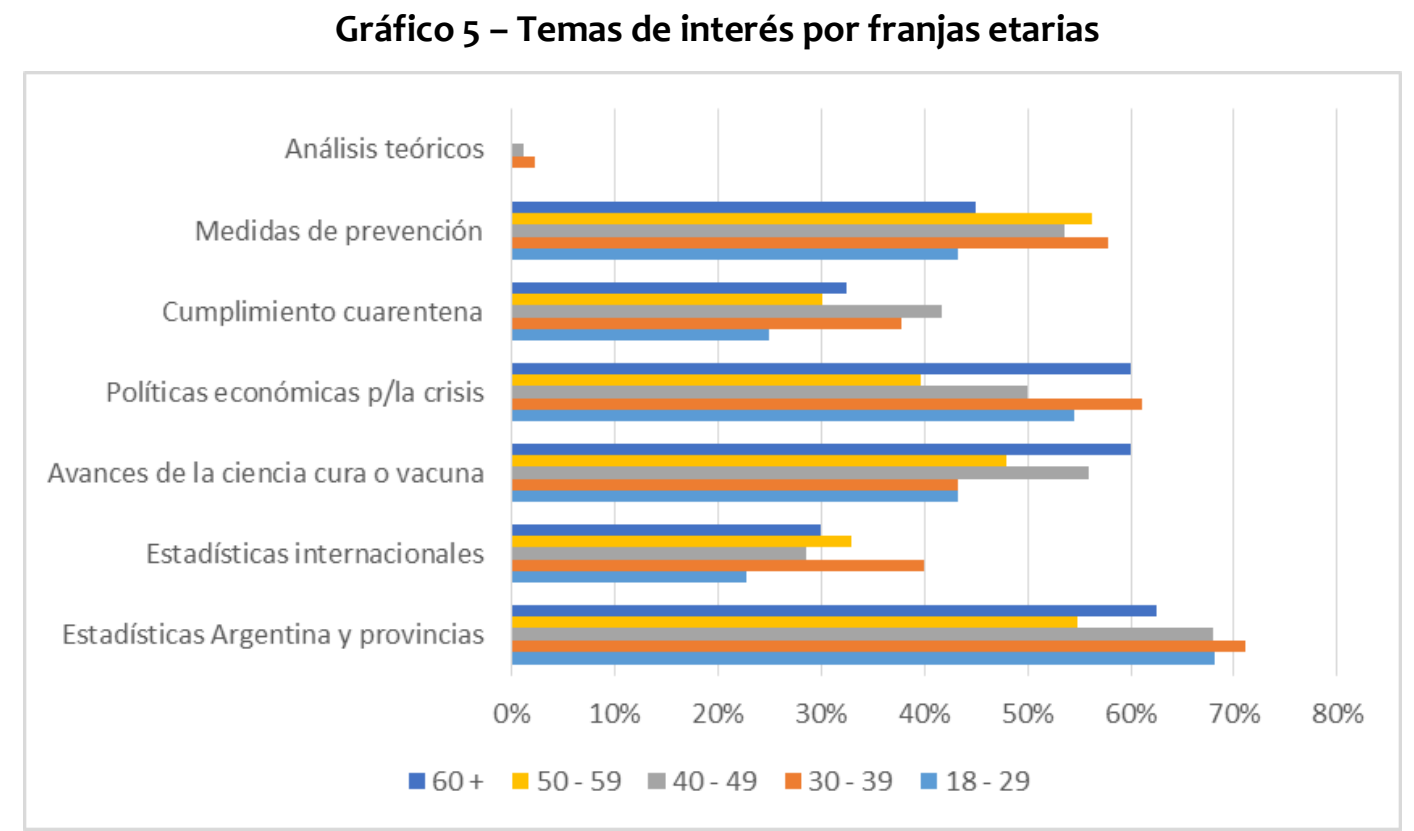

Fuente: Observatorio de Comunicación y Temáticas Sociales - FaDeCS - UNCO

De la totalidad de personas encuestadas, las mujeres se muestran más interesadas por las medidas de prevención y los varones por las estadísticas y las políticas económicas para ayudar a superar la crisis. Seguramente estos datos podrán analizarse desde otras miradas disciplinares con la consecuente profundización del tema pero, en principio, nuestro supuesto de trabajo es que estos datos de interés por el tipo de noticias según la identidad autopercibida reafirman la división sexo-genérica del trabajo: las mujeres escogen más noticias de prevención porque según las normas de género se dedican más a las actividades hogareñas y de cuidado; mientras que los varones eligen consumir más sobre estadísticas de contagios y política puesto que se abocan más a la cuestión pública, a lo macro, es decir, a la vida pública.

Ahora bien, a los efectos de comprender la eficacia de los procesos de prevención y promoción de la salud en época de crisis sanitaria, es menester resaltar el alto grado de confianza que la información producida y difundida por los gobiernos fue adquiriendo en el conjunto de la población. Efectivamente, el resultado de la primera encuesta determinó que tanto los gobiernos (nacional, provinciales y locales) como los sistema de Salud de éstos ámbitos constituyían y constituyen fuentes confiables o muy confiables en este escenario de crisis (Gráfico 6). 
Gráfico 6 - Confianza en las fuentes

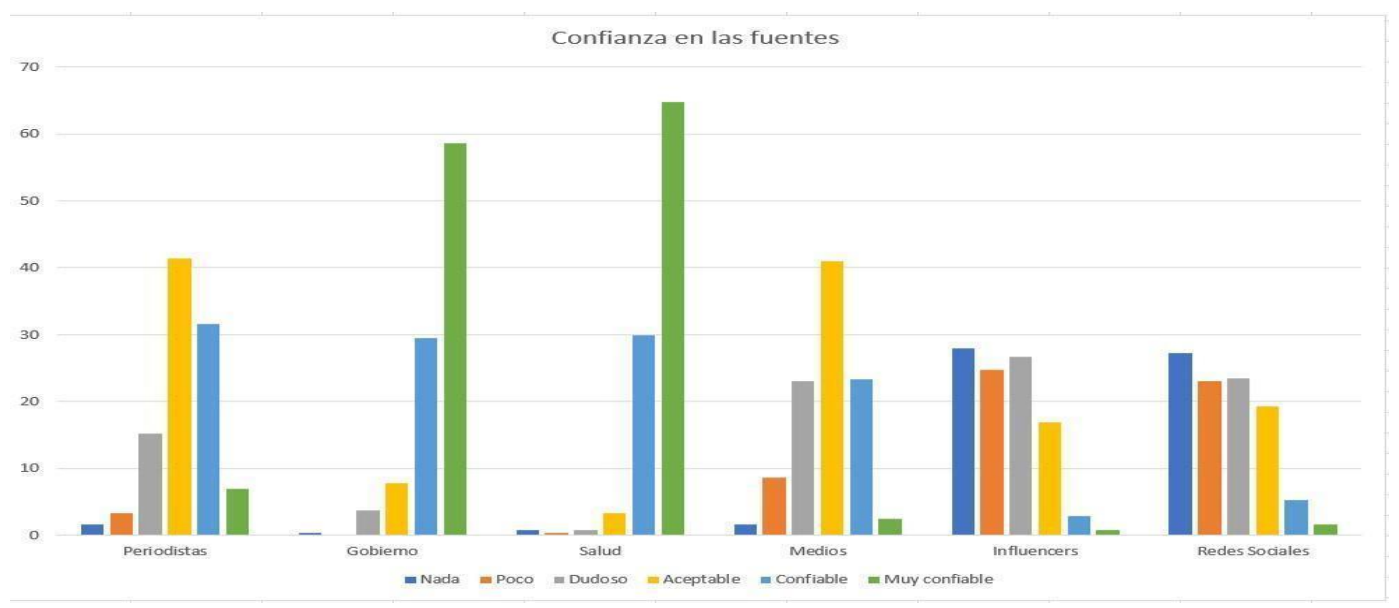

Fuente: Observatorio de Comunicación y Temáticas Sociales - FaDeCS - UNCO

Al mismo tiempo, los/as periodistas y los medios de comunicación logran consolidar un grado "aceptable" de confianza, fundamentalmente en función de dos estrategias de construcción de noticias que, como sostiene Mónica Petracci (2015), permiten observar los circuitos mediante los cuales los/as agentes sanitarios/as, las autoridades políticas y los/as periodistas interactúan. Así, en términos generales durante el primer mes de cuarentena el periodismo optó, por un lado, por la reproducción de partes sanitarios oficiales (como vimos muy confiables para la gente) y, por otro lado, por el espacio constante otorgado a especialistas para la explicación de las particularidades del virus y de las medidas de prevención (como vimos también un sector muy confiable para la población).

El grado de confianza en la información que circula por las redes sociales y en los/as denominados/as influencers es insignificante $y$, al mismo tiempo, mucho mayor el grado de desconfianza. Es que si bien a través de internet se amplían las fuentes de información sobre salud que pueden contribuir en los procesos de prevención y promoción en época de crisis, no es menos cierto que, como sostienen EspinozaPortilla y Mazuelos-Cardoza (2015, p. 3), "la falta de evidencia científica de la información que pueda ser compartida a través de las redes sociales puede influenciar las actitudes y las creencias de los usuarios", generando un círculo de desinformación (información falaz, confusa, sesgada, alarmista, etc.) que, en palabras de PorrocheEscudero (2017), bloquea el derecho a la información.

La desconfianza en las redes evidenciada en la Patagonia norte va en línea con el trabajo producido por Pont, Besalú, Rovira, Castelo y Sánchez (2019) en el cual concluyen que "la formación otorga un grado de capacidad crítica respecto a las informaciones políticas y se percibe como un factor a tener en cuenta en términos democráticos ante la proliferación de fake news" (PONT et. al., 2019, p.8). En el mismo sentido, el informe "Navegando la infodemia" del Reuter Institute y la Universidad de Oxford (2020) muestra que se trata de una tendencia a nivel mundial, con mayor confianza en organizaciones de salud pública nacionales e internacionales y (excepto en España y los EEUU) en sus gobiernos nacionales; confianza en los/as científicos/as; y una caída en la confianza en plataformas sociales ${ }^{19}$.

${ }^{19}$ El estudio completo puede consultarse en línea en: https://reutersinstitute.politics.ox.ac.uk/navegando-la-infodemiaasi-consume-noticias-e-informacion-sobre-coronavirus-espana-argentina-otros-paise 


\section{REDES SOCIALES Y CIRCULACIÓN DE LA INFORMACIÓN}

Aun cuando la información que circula por las redes sociales no goza de buenos índices de confianza, lo cierto es que la mayor parte de las personas de Río Negro y Neuquén comparten más noticias y recomendaciones útiles de prevención a través de las redes sociales que antes del inicio de la cuarentena. En general, hay una tendencia a convertirse en distribuidores de este tipo de informaciones a sus propios contactos. Pero también ven a las redes como un canal de distracción y entretenimiento; por eso, un $21,2 \%$ de las personas dicen distribuir memes entre sus contactos y sus grupos. Haciendo la distinción por edades, se observa que la decisión de compartir noticias y recomendaciones es propia de todos los segmentos pero con mayor énfasis en los mayores de 50 años y que la lógica de compartir memes es más propia de los y las jóvenes (Gráfico 7).

\section{Gráfico 7 - Destino de la información que reciben por franja etária}

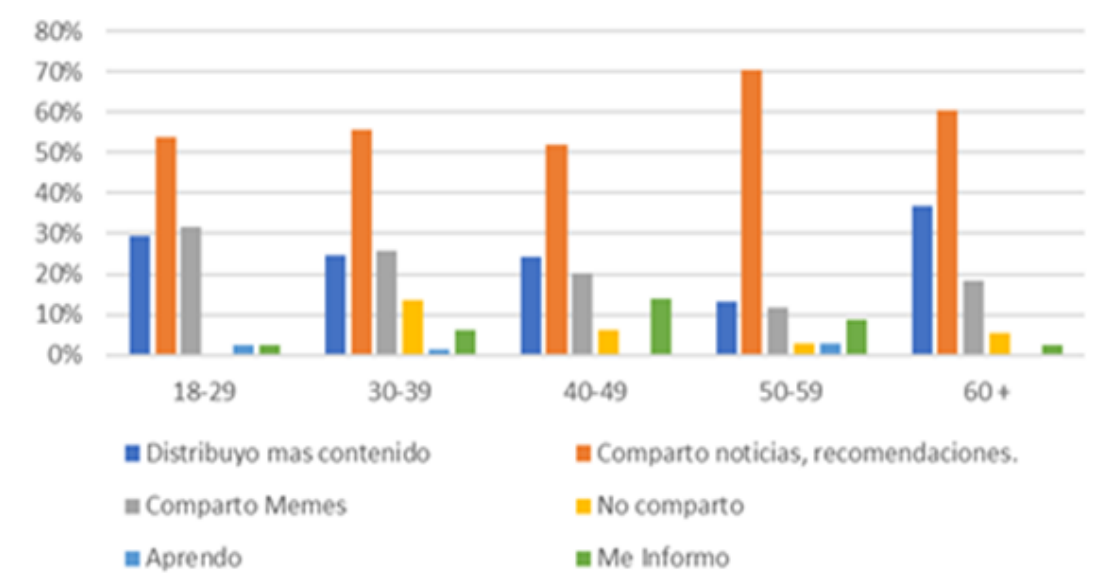

Fuente: Observatorio de Comunicación y Temáticas Sociales - FaDeCS - UNCO

Si se observa el Gráfico 8 y el Cuadro 3, vemos que Facebook es la red social más utilizada para informarse, sobre todo por parte de las mujeres; los varones -un poco más que las mujeres- utilizan WhatsApp y Twitter, y las mujeres bastante -más que los varones- Instagram; ambas identidades de género se vuelcan por los sitios digitales (a quienes ubican como redes) para mantenerse al tanto de los hechos informativos respecto del Coronavirus. Así mismo, esa red es utilizada con mayor intensidad en los extremos: de 18 a 29 y de 60 y más años. WhatsApp es la red de las personas de mayor edad e Instagram de los de menos edad. $Y$ Twitter se ubica como la red informativa de los segmentos medios: entre 30 y 49 años.

El hecho de que Facebook sea la red social más utilizada parece estar vinculado no sólo con el hecho de ser la más antigua, sino también a que es la que mayor presión social ejerce para mantener a sus usuarios conectados. Como sostiene José Van Dijck (2016), esta red se ha convertido en un espacio fundamental para la acumulación de capital social, pues "no estar en Facebook, supone no ser invitado a fiestas o no recibir información sobre eventos importantes; en síntesis, quedar desconectado de una dinámica de la vida pública que parece muy atractiva" (VAN DIJCK, 2016: 54). En este sentido, si el hecho de mantener las relaciones sociales ha sido históricamente un trabajo feminizado, la primacía de su uso por parte de personas que se auto-perciben como mujeres vendría a reforzar ese rol de género. 


\section{Gráfico 8 - Redes Sociales utilizadas según identidad de género autopercibida.}

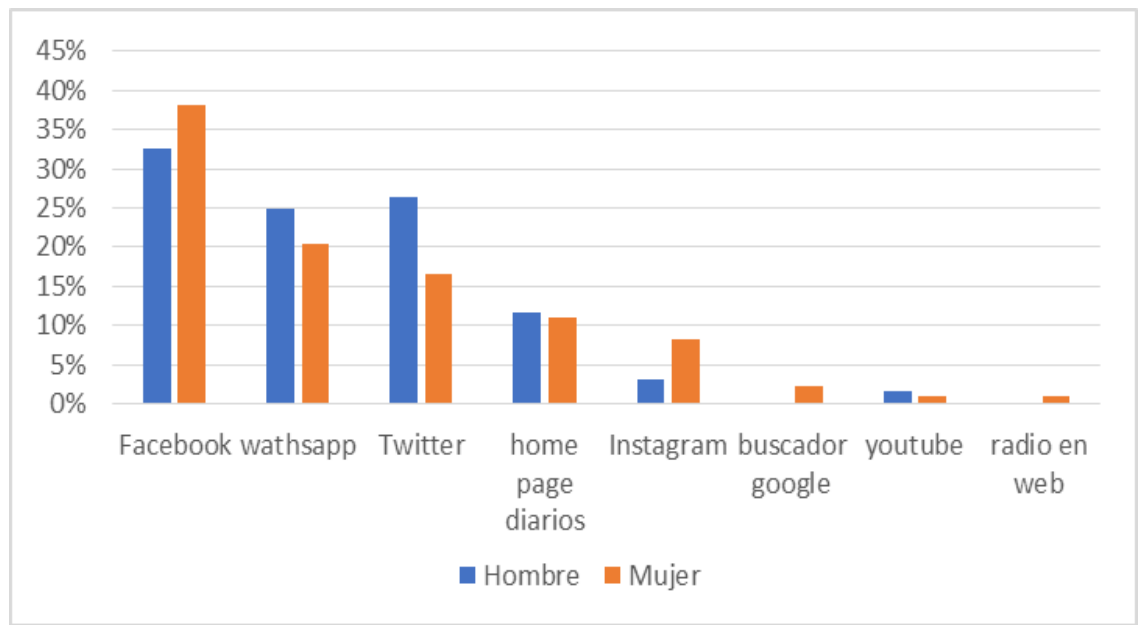

Fuente: Observatorio de Comunicación y Temáticas Sociales - FaDeCS - UNCO.

Cuadro 3 - Redes sociales usadas con fines informativos según franja etaria.

\begin{tabular}{|l|l|l|l|l|}
\hline \multicolumn{1}{|c|}{ Franja etaria } & \multicolumn{1}{|c|}{ WhatsApp } & \multicolumn{1}{c|}{ Twitter } & \multicolumn{1}{c|}{ Facebook } & \multicolumn{1}{c|}{ Instagram } \\
\hline $18-29$ & $7,7 \%$ & $23,1 \%$ & $46,2 \%$ & $15,4 \%$ \\
\hline $30-39$ & $19 \%$ & $26,2 \%$ & $31 \%$ & $8,3 \%$ \\
\hline $40-49$ & $21 \%$ & $22,2 \%$ & $33,3 \%$ & $3,7 \%$ \\
\hline $50-59$ & $34,3 \%$ & $13,4 \%$ & $35,8 \%$ & $3 \%$ \\
\hline$>60$ & $25,6 \%$ & $15,4 \%$ & $41 \%$ & $2,6 \%$ \\
\hline
\end{tabular}

Fuente: Observatorio de Comunicación y Temáticas Sociales - FaDeCS - UNCO.

Ahora bien, si conocer y reconocer las prácticas informativas de la población a través de las redes sociales es una instancia medular para comprender los procesos de prevención y promoción de la salud en momentos de crisis, es porque constituyen una de las maneras privilegiadas y permanentes de acceso a la información y, en el mismo acto, permiten la reproducción individual de esa información. De allí la importancia de prestar especial atención a la información/desinformación, su circulación y circularidad.

En efecto, los contactos de cada uno y cada una en las redes sociales constituyen la principal vía de acceso a la información, lo cual permite pensar en cierta "circulación circular" de la información, fundamentalmente, en aquellos casos en los que sus prácticas informativas no suelen focalizar en los denominados medios tradicionales. Es que, al igual que el proceso de circularidad de la información descrito por Pierre Bourdieu (2000) respecto de la televisión, en las prácticas de consumo informativo mediante redes sociales se produce una rotación similar toda vez que, como vemos en el Gráfico 9, el 38,4\% de las personas acceden principalmente a la información que les llega a través de sus contactos mientras que casi el 50\% (Gráfico 10) manifiesta una tendencia a compartir la información a la que tiene acceso (que busca o que le aparece) con sus contactos. 


\section{Gráfico 9 - Modo de acceso a la información}

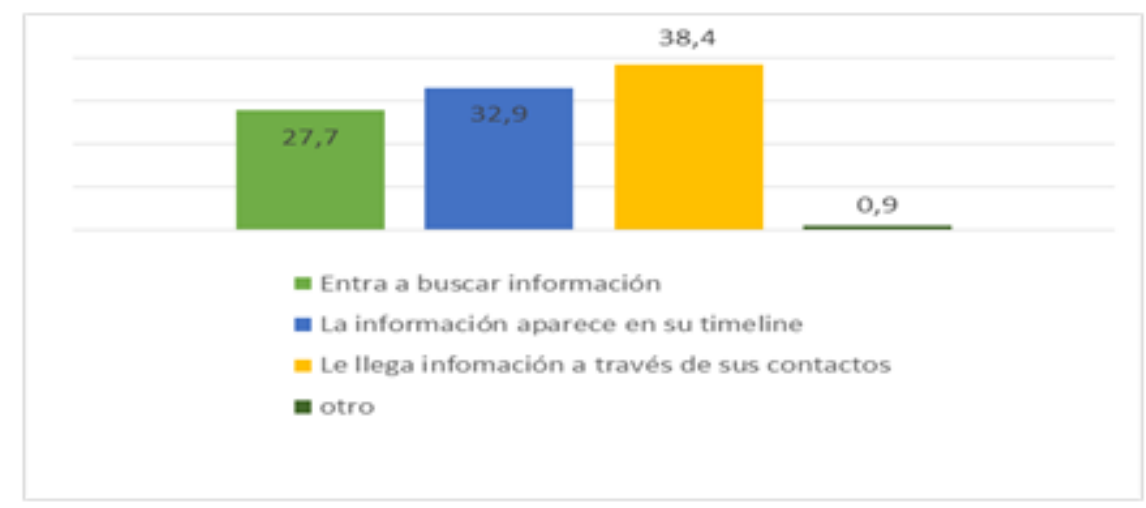

Fuente: Observatorio de Comunicación y Temáticas Sociales - FaDeCS - UNCO.

Gráfico 10 - Acciones que realizan en las Redes Sociales

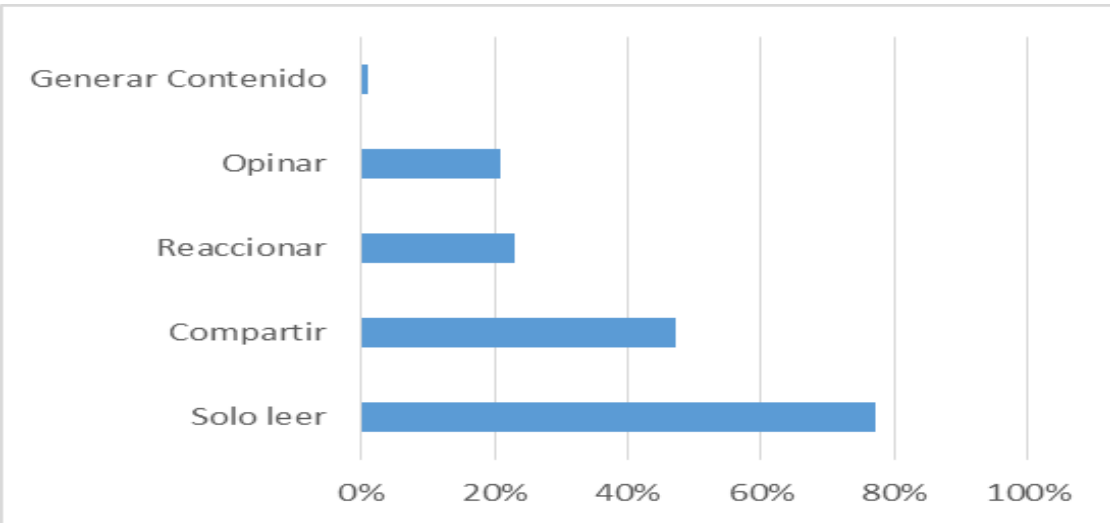

Fuente: Observatorio de Comunicación y Temáticas Sociales - FaDeCS - UNCO.

Es por la desconfianza en las redes sociales (Gráfico 11), pues para cerca del $10 \%$ la información en redes sociales es no creíble y el $67 \%$ la pone en duda, que la mayoría de la gente dice que sólo lee los contenidos en sus muros. Sin embargo, en buena proporción los comparte, opina o reacciona dando continuidad así, de manera más o menos directa, a la circulación y/o valorización de informaciones y noticias que no siempre, o que pocas veces, consideran creíbles. 


\section{Gráfico 11 - Credibilidad asignada a las Redes Sociales ante noticias del COVID-19}

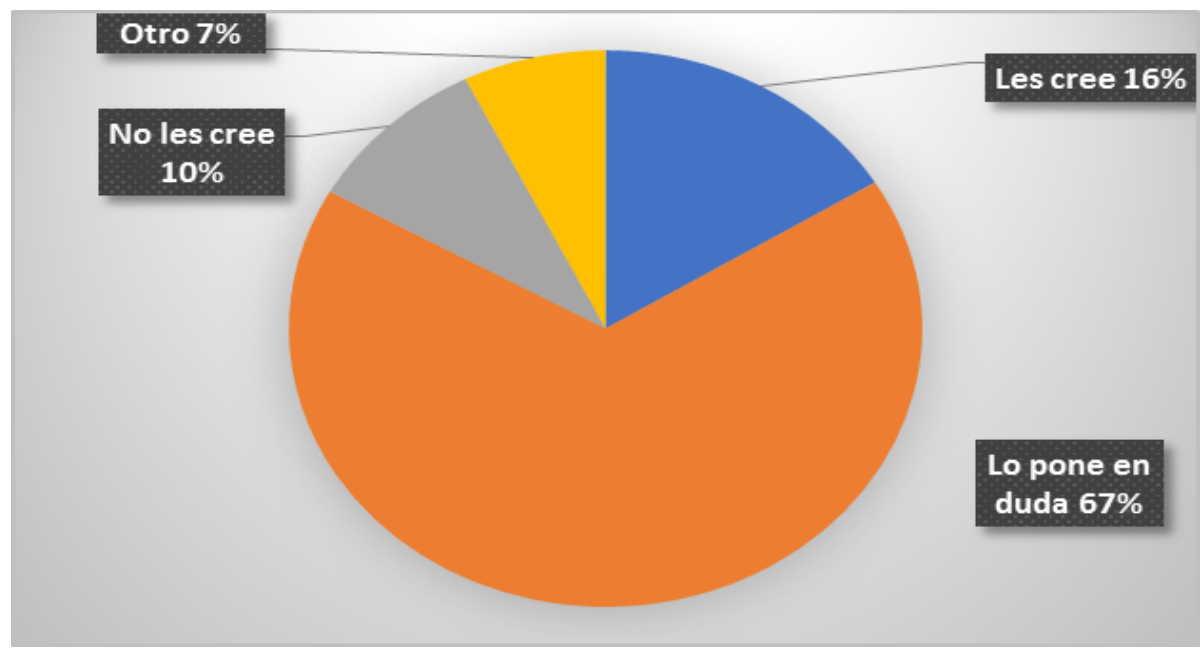

Fuente: Observatorio de Comunicación y Temáticas Sociales - FaDeCS - UNCO.

La diferencia de percepción es notable: un 54,8 \% afirma que la información que llega a través de las redes sociales es confusa, contra un $26,1 \%$ de los medios. Es decir, las redes sociales son la tecnología más utilizada para informarse sobre la pandemia y sus efectos pero -a la vez- constituye el soporte menos creíble para la mayoría de la gente entrevistada. El uso de las redes sociales podría interpretarse así como una práctica constitutiva de una "cultura de la conectividad" (Van Dijck, 2016) que, frente a un escenario en el que se reduce al mínimo la interacción offline, se convierte en el espacio principal para intercambiar y formar opiniones, "estar en contacto" con otros/as y/o compartir espacio público. En este sentido, se podría afirmar que, aun sabiendo de los riesgos de informarse a través de ellas, la población decide continuar empleando las redes en tanto reconocerían allí un espacio de comunidad, un espacio de interacción social. Es por ello que reside aquí uno de los datos sustanciales para idear una estrategia clara de promoción y prevención.

\section{Gráfico 12 - Consideración de la información recibida por las personas encuestadas}

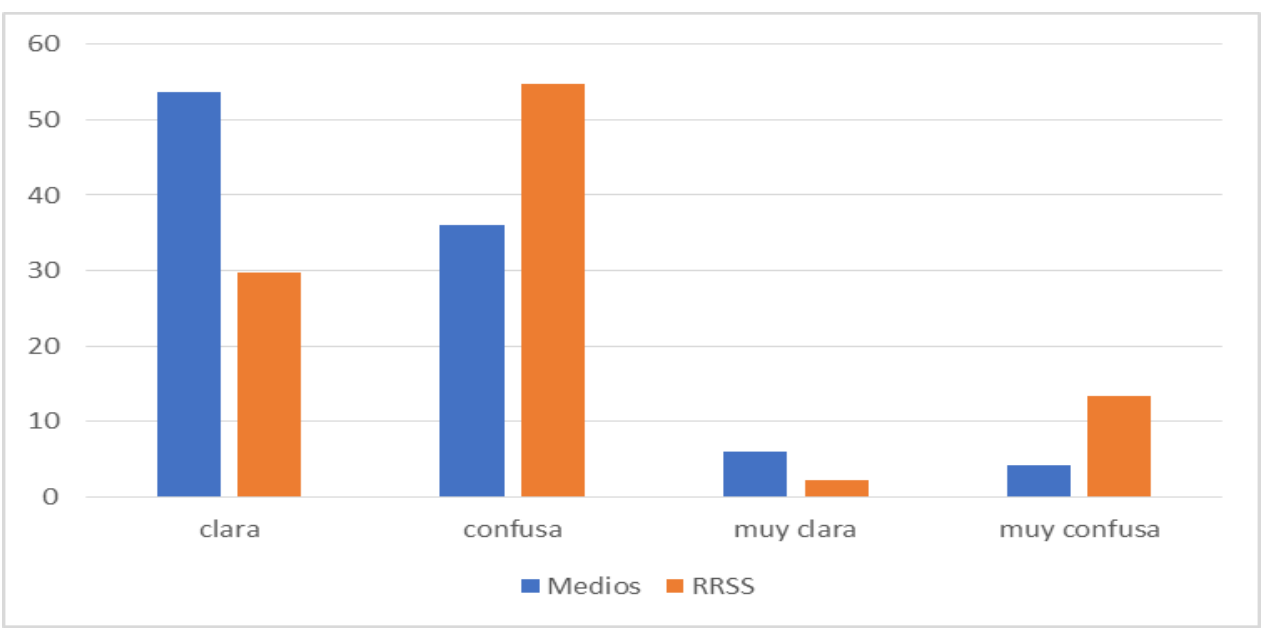

Fuente: Observatorio de Comunicación y Temáticas Sociales - FaDeCS - UNCO. 
Ahora bien, consultado/as acerca de quién consideran que tiene la responsabilidad primaria de chequear la información que reciben, el 46,2\% de las personas encuestadas dicen que es de ellas mismas. En segundo lugar, el 42,2 \% dice que es de los y las periodistas. Es muy escaso el porcentaje que asegura que las personas consideradas influencers en las redes sociales o que los gobiernos deberían ocuparse de la confrontación de la información (Gráfico 13).

\section{Gráfico 13 - Responsabilidad del chequeo de la información}

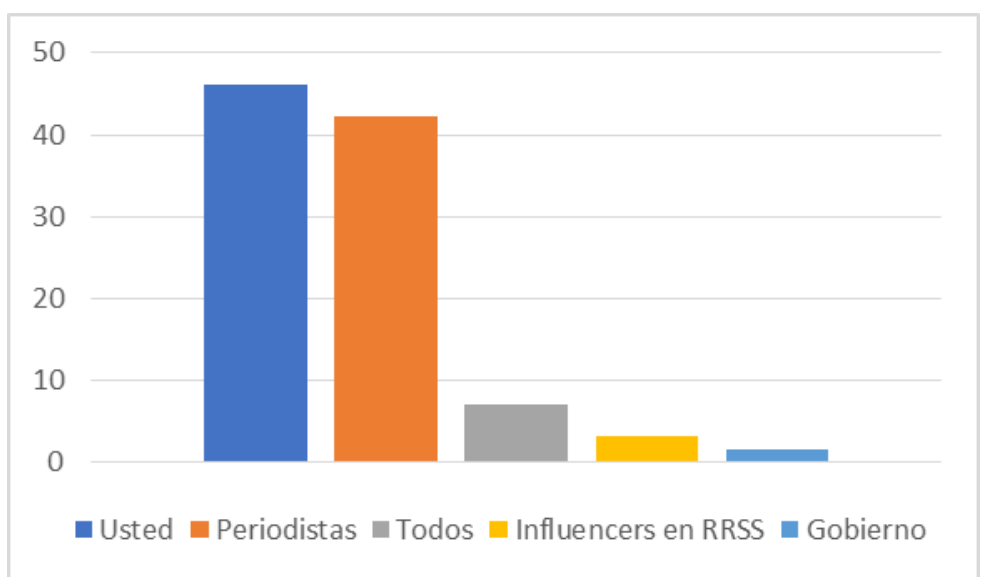

Fuente: Observatorio de Comunicación y Temáticas Sociales - FaDeCS - UNCO.

De manera que es posible plantear una especie de tensión entre información, desinformación y monitoreo ciudadano, por lo menos en época de crisis sanitaria. En esa tensión, el monitoreo, la capacidad y disposición a contrastar, constituyen el espacio, el "margen de maniobra" (WOLTON, 2007), la primera trinchera contra la desinformación y sus efectos.

\section{REFLEXIONES FINALES}

Nos propusimos en este escrito identificar las principales prácticas de consumo informativo respecto del Covid-19 en Patagonia norte, Argentina, a los efectos de comprender más acabadamente los procesos comunicacionales relacionados a la prevención y promoción de la salud en tiempos de crisis.

Desde que comenzó la cuarentena, casi el 60 \% de las personas encuestadas afirma haber cambiado sus prácticas de consumo informativo; la intensidad de tales cambios depende de los segmentos de edad pues las variaciones más pronunciados se dan entre las personas mayores de 30 años, en buena medida por la necesidad de incorporar las nuevas tecnologías a sus vidas cotidianas y de disponer de mayor tiempo para informarse $y$ formarse en el consumo de medios.

Del presente estudio, se infiere que la permanencia en cuarentena obligatoria disparó una serie de alteraciones profundas en las rutinas informativas diarias de la población encuestada. Podría decirse que las nuevas prácticas tienen algunos ejes comunes:

- Aumenta el consumo de televisión. Es el difusor más fuerte de noticias dentro del hogar que, de acuerdo a nuestro relevamiento anterior, desplaza a la radio en las preferencias informativas.

- La televisión local adquiere para mucha gente un rol fundamental en las prácticas informativas. Es el aparato que está encendido durante casi todo 
el día, y genera mayor atención en los horarios de los noticieros locales/nacionales.

- Se amplía la oferta de medios. En la mayoría de los casos, se incorporan medios digitales, radios de otros lugares, entre otros.

- La confianza está fundamentalmente del lado de las fuentes oficiales, tanto locales, como nacionales e internacionales. $Y$ de efectores de salud.

- Las redes sociales cobran protagonismo en el uso recreativo, pero también en el plano de la sociabilidad y como canal de información. En este sentido, aunque no son fuentes de información confiables para el tema Pandemia, su uso e interacción es alto y continúa teniendo legitimidad social.

- La sobrecarga de información lleva a un pequeño grupo a preservarse en el consumo: se expone menos horas, selecciona más criteriosamente los medios, abandona redes o limita el consumo al máximo. Este comportamiento se registra más fuertemente en la población más joven.

- Cruzar información, descartar, chequear, son tres verbos repetidos en el curso de esta indagación. El monitoreo ciudadano cobra mayor relevancia.

Como vimos, el resultado de nuestras mediciones va en sintonía con los estudios más importantes que se vienen realizando a nivel nacional e internacional. Es así que podríamos afirmar que los cambios de prácticas informativas en los países del norte, se han ido trasladando casi como en espejo al hemisferio sur a medida que -en palabras de la OMS- América se fue convirtiendo en el nuevo epicentro de la Pandemia.

Es claro que estas tendencias informativas en tiempos de cuarentena dispararán nuevas prácticas cuando las medidas de aislamiento se relajen. Es posible que se instalen como rutinas la lectura de medios en línea; que la caída de la prensa escrita se acelere por la falta de ingresos publicitarios y de ventas; que haya una vuelta a la escucha de radio en movimiento (por ahora desplazada por el imperio de la televisión dentro del hogar $)^{20}$ y que nuevos medios se sumen a la dieta informativa de cada persona.

Pero vale formular a modo de hipótesis (y tomando los informes internacionales antes citados) otros cambios que tienen que ver con la confianza, la credibilidad y las actitudes frente a las noticias falsas y las campañas de desinformación. Nuestros estudios Covid-1 y Covid-2, nos alientan a suponer que la desconfianza de la gente hacia la información que viene a través de redes sociales se mantendrá, y que exigirá a esas plataformas medidas concretas para evitar ser engañada ${ }^{21}$.

Otra hipótesis probable es que la gente mantenga una actitud crítica con las noticias, y que las someta al contraste con otros medios, en cualquier plataforma posible, en tanto se considera responsable primaria del chequeo de la información (datos que se desprende de nuestro estudio Covid-2). En este sentido, la incorporación de estas

\footnotetext{
${ }^{20}$ En el caso particular de la radio, durante la pandemia se observan fenómenos de recuperación de viejos géneros, como el radio-teatro o la reactivación de la función escolar-educativa de la radio fundamentalmente en entornos rurales. Estas prácticas radiales podrían abrir el abanico de programación actual y potenciar su escucha una vez transcurrido el período de aislamiento

${ }^{21}$ El 28 de mayo de 2020, el presidente de Estados Unidos ordenó anular la supuesta inmunidad de las plataformas digitales. El decreto de Trump propone una revisión de "las reglas vigentes en materia de publicación, jerarquización, visibilización o remoción de contenidos en las plataformas digitales, hoy sostenidas en la Communications Decency Act.", según explica el investigador Martín Becerra. El artículo de análisis completo puede consultarse en línea aquí: https://martinbecerra.wordpress.com/2020/05/29/trump-pateo-el-hormiguero-digital/
} 
prácticas informativas en contexto de pandemia podría generar un crecimiento del poder ciudadano en tanto al incorporar el hábito de seleccionar criteriosamente sus fuentes de información, también trabajaría más selectivamente en la formación de su opinión. En consecuencia esto podría generar un escenario tendiente a incrementar la democracia.

En este sentido, pasado el estado de shock de la población, es deseable que ese espíritu crítico (la guerrilla semiológica que pregonaba Eco en La Estrategia de la llusión de 1985) se extienda a los discursos oficiales y no oficiales, para devolver a la ciudadanía su rol de confrontación permanente.

\section{REFERÉNCIAS}

ALBARDONEDO, V.; CUBERLI, M. La comunicación como acto y disciplina en la formación de médicos. Revista Pilquen, ano XI, n. 11, 2009.

ALCANTARA LOPEZ, R. Comunicación \& internet \& salud: puntas de un iceberg Ilamado e-salud. In: DEL POZO CRUZ et al. (Coord). Medios de comunicación y salud. Sevilla: Astigi, 2015.

ARIAS-ROBLES, F. La credibilidad de los contenidos informativos em internet para los 'nativos digitales': estudio de caso. Palabra Clave, v. 17, n. 3, 2014.

BENTON, J. The coronavirus traffic bump to news sites is pretty much over already. In: NIEMAN lab foundation at Harvard. Disponível em: https://www.niemanlab.org/2020/04/the-coronavirus-traffic-bump-to-news-sites-ispretty-much-over-already/ 2020. Acesso em: 2020.

BERGERO, F. Pactos de lectura en sitios de noticias digitales: desencuentros en la red. 2013. Tesís (Maestría en Periodismo y Medios de Comunicación Social)Universidad Nacional de La Plata. 2013.

BOURDIEU, P. Sobre la televisión. Barcelona: Anagrama. 2000

BOURDIEU, P. ¡Viva la crisis! Por la heterodoxia en ciencias sociales. In: BOURDIEU, P. Poder, derecho y clases sociales. Bilbao: Editorial Desclée de Brouwer, 2001.

CASTELLS, M. Comunicación, poder y contrapoder en la sociedad red. Telos, n. 74, 2008.

CEREZO, P. El impacto de la pandemia en la prensa. In: WHITE Paper 2020. Disponível em: http://evocaimagen.com/dosieres/dosier-evoca-09-medios-y-coronavirus.pdf. Acesso em: 2020.

DIAZ, H.; URANGA, W. Comunicación para la salud en clave cultural y comunitaria. Revista de Comunicación y Salud, v. 1, n. 1, p. 113-124, 2011.

ESPINOZA PORTILLA, E.; MAZUELOS CARDOZA, C. Desinformación sobre temas de salud en las redes sociales. Revista Cubana de Información en Ciencias de la Salud, La Habana, v. 31, n. 2, 2020. 
FEO ACEVEDO, C.; FEO ISTÚRIZ, O. Impacto de los medios de comunicación en la salud pública. Saúde em Debate, v. 37, n. 96, p. 84-95, 2013.

HERNÁDEZ SAMPIERI, FERNÁNDEZ COLLADO, BAPTISTA LUCIO. Metodología de la investigación. México: McGraw-Hill Interamericana. 2006.

LÓPEZ-GARCÍA, X; NEGREIRA-REY, M. C.; RODRÍGUEZ-VÁSQUEZ, A. I Cibermedios hiperlocales ibéricos: el nacimiento de una nueva red de proximidad. Cuadernos Info, n. 39, p. 225-240, 2016.

LÓPEZ GARCÍA, X. Ciberperiodismo en la proximidad. In: CORREIA, J. C. (Org.). Ágora: jornalismo de proximidade: limites, desafios e oportunidades. Portugal: Livros LabCom. 2012.

LOPEZ, GARCÍA, X. "Regional and local online media: tools for making participatory and hyperlocal journalism become reality”. In: CORREIA, J. C. (Org.). Ágora: jornalismo de proximidade: limites, desafios e oportunidades. Portugal: Livros LabCom. 2012.

OBREGÓN, R. Un panorama de la investigación, teoría y práctica de la comunicación en salud. Revista Folios, n. 23, p. 13-29, 2010.

PETRACCI, M. Ámbitos público y mediáticos en comunicación y salud. Revista Correspondencia \& Análisis, n. 5, p. 269-287, 2015.

PONT, Carlos; BESALU, Reinald; ROVIRA, Edgar; CASTELO, Santi; SÁNCHEZ, Metzeri. Análisis de la credibilidad de la información política en el entorno digital (Facebook, WhatsApp, prensa digital y televisión). 2019. Disponível em: https://www.upf.edu/documents/220602201/0/C\%C3\%A1tedraldeogramaUPF_An\%C3\%A1lisis+de+la+credibilidad+de+la+informaci\%C3\%B3n.pdf/f3e $546 \mathrm{db}-4819$ 5a11-6838-b1cda874e6a7. Acesso em: 2020.

PORROCHE-ESCUDERO, A. Problematizando la desinformación en las campañas de concientización sobre el cáncer de mama. Gac Saint, v. 31, n. 3, p. 250-252, 2017.

REUTER INSTITUTE; OXFORD UNIVERSITY. Navegando la infodemia: así se consume y califican las noticas y la información sobre coronavirus la gente en seis países. 2020. Disponível em: https://reutersinstitute.politics.ox.ac.uk/navegando-la-infodemia-asiconsume-noticias-e-informacion-sobre-coronavirus-espana-argentina-otros-paises. Acesso em: 2020.

ROST, A.; PUGNI RETA, M. E.; APESTEGUÍA, E. Cómo navegan los usuarios de los sitios de noticias. In: PERIODISMO digital en Argentina: diseño, interactividad, hipertexto y multimedialidad en sitios de noticias. General Roca, 2008.

SAMUEL-AZRAN, T.; HAYAT, T. La credibilidad de las noticias digitales: el vínculo es más impactante que la fuente. Comunicar, v. 60, p. 71-80, 2019.

SÁNCHEZ-NAVARRO, J.; ARANDA, D. Internet como fuente de información para la vida cotidiana de los jóvenes españoles. El Profesional de la Información, v. 20, n. 1, p. 32-37, 2011. 
SCHLEIFER, P. "Comunicación mediática y noticias regionales: la televisión pública en Río Negro”. Revista de Comunicación, v. 17, n. 1, 2018

SOLARO, L. Hábitos de lectura y participación de usuarios patagónicos. In: ROST, A. et al. Periodismo transmedia: la narración distribuida de la noticia. General Roca, 2016.

VAN DIJCK, J. La cultura de la conectividad. Buenos Aires: Siglo XXI. 2016

WOLTON, D. Pensar la comunicación. Buenos Aires: Prometeo Libros. 2007. 